\title{
Formation in Baccalaureates and Masters of General Cultural and Professional Scopes in Field of Health Care
}

\author{
Abaskalova Nadegda Pavlovna*, Aizman Roman Idelevich \\ Department of Anatomy, Physiology and Safety of life at FGBOU VPO “Novosibirsk State Pedagogical University”, Honored worker \\ of higher school of Russian Federation, Novosibirsk \\ *Corresponding author: Abaskalova2005@mail.ru
}

Received March 16, 2014; Revised May 12, 2014; Accepted June 04, 2014

\begin{abstract}
In the article the general characteristics of contemporaryy formation, training competent authorities in questions of the health care formation are examined. Is described the mechanism of training baccalaureates and masters through the educational programs, which reflect the formation of professional scopes. The concept of health monitoring is represented.
\end{abstract}

Keywords: baccalaureates, masters, the health care formation, professional scopes, monitoring

Cite This Article: Abaskalova Nadegda Pavlovna, and Aizman Roman Idelevich, "Formation in Baccalaureates and Masters of General Cultural and Professional Scopes in Field of Health Care.” American Journal of Educational Research, vol. 2, no. 6 (2014): 378-382. doi: 10.12691/education-2-6-8.

\section{Introduction}

1.1. Education is one of the most effective mechanisms of personality development, improving the social status and security of citizens. Now enough, the problem of competence of the graduates of educational institutions is particularly acute on a labor market, because competitive young specialist is caused not only by his professional knowledge and skills, but also the presence of certain qualities and personality traits. Thus, the task of preparing graduates with the highest level of professional and personal competence, who are able to adapt to the changing conditions of professional activity, in other words, the creation of competent and competitive professionals, is essential for professional educational institution.

Now there is a contradiction between «qualification» approach in education and character of the following professional activity of graduates [10].

1.2. Academician A. Novikov [8] considers that for a development of education in the conditions of occurrence in world economic community has to have the following main tendencies:

- person must realize his potential, not to perform monotonous routine operations;

- person should make his own decisions and count on further professional and cultural growth;

- person is an active subject, which is free to dispose his main capital - his own qualification;

- each person is compelled to change often not only a work place, but also a profession as the market is mobile, thus, education has to be convertible;

- only $20 \%$ of the busy population usually work in the specialty which received in basic professional education, and $42 \%$ of youth change the professions in the first two years upon termination of professional educational institution;

- economics of Human Resources replaced the resource economy. Countries that can provide a higher level of education, training and skill of the people in all its requirements for general education level and professional qualifications of each individual employee, will focus on developing the spiritual facilities of man, which are a precondition for the ability to work.

The state educational standards of higher education of new generation say that it is necessary to satisfy a growing demand of society for new competences [9].

\section{Objectives}

2.1. The basis of modern educational standards is a formation of the following basic competencies of the modern person:

- informational (the ability to search, analyze, transform, apply information to solve problems);

- communicative (effectively to cooperate with other people);

- self-organization (ability to set goals, plan, take responsibility for health, full use of personal resources);

- self-education (readiness to design and carry out own educational trajectory throughout all life, providing success and competitiveness).

Formation at undergraduates of common cultural and professional competences in area of design of application of health saving technologies is an important task as questions of preservation, development of health, formation the culture of health are reflected in educational standards of new generation for all education levels. 
The culture of a healthy lifestyle of the personality is a part of the general culture of the person which reflects his system and dynamic state caused by a certain level of special knowledge, physical culture, social and spiritual values, which are acquired as a result of upbringing and self-upbringing, motivational and valuable orientation, the education and self-education embodied in practical activity, and also in physical and psychological health.

New Federal State Educational Standards (FSES) reflect questions of preservation and development of pupils' health therefore the school has to pass a way in the direction of creation of innovative health saving pedagogical technologies from modeling with children of the problem situations directed on information to transfer and implementation of scheduled maintenance, from the organization of health saving space and formation of requirement for a healthy lifestyle to creative and volunteer movement and competence formation "to be healthy» $[6,7,9]$. The new, competent teacher in the solution of the matters is necessary for new school.

The health saving pedagogics differently builds the relations between education and upbringing, transfers upbringing to a framework of life-supporting process which is directed on preservation and enhancement of the child's health. Health saving educational technologies are programs and methods which are directed on upbringing at children culture of health, personal qualities which promote its preservation and strengthening, representation formation about health as values, motivation on a healthy lifestyle [1,2,11].

2.2. Cardinal changes in the national system of the higher professional education are connected as with fundamental factors of the world's evolution of educational environment, and with the current processes of economic-sociological and demographic development. Questions of optimization of children's academic, psychological and physical activity and providing in educational institutions of health saving space are reflected in some of normative documents.

Organizational conditions are created for development of network «health schools» through adoption of the Approximate provision on the Center of assistance to strengthening of health trainee, pupils of educational establishment (the order No. 1418 of 15.05.2000). Recommendations «About reduction in compliance with existing sanitary standards of training's conditions and stay of children in educational establishment» (the order No. 26/4100-6 of 30.10.2003) are developed.

The program «Health» at school assumes realization in such main directions:

- creation of a single, focused on the preservation of health, developing space in the educational establishment that allows students in the creative life to form the key competence "be healthy" and to organize a healthy lifestyle.

- improvement of a condition of intra school space by means of creation of audiovisual image of establishment focused on health.

- the organization of conditions for social advertizing values of a healthy lifestyle in teenage subculture in school and the residential district.

- providing conditions for complex rehabilitation (pedagogical, social, psychological, medical, etc.) in the conditions of educational institution.
- the creation psychological and social resources for maintenance of all participants of pedagogical interaction.

2.3. Directions forming the base of personal health culture in schools are:

1. The counteraction to specific risk factors of health's violation which are connected with the organization of pedagogical and educational activity.

2. The ensuring competitiveness of the healthy lifestyle (HL) among other ways of pastime of people.

3. The providing an one-orientation of all social and pedagogical influences and providing at the expense of this resonance of HL.

4. The development of creative manifestations of the person, his self-education and self-knowledge in the sphere of culture of health and HL.

5. The assessment of activity's quality of educational institutions includes integrated indicators of health and HL of all participants of pedagogical process.

Health saving maintenance of pedagogical and educational process is a complex of actions which includes the analysis and differentiation of educational routes of pupils in comparison to indicators of training's success, results of testing, forecasting and correction of a functional condition of each pupil, taking into account extent of his adaptation to educational process, working capacity and health.

Health saving technologies in the educational environment are the system of measures for protection and strengthening of health trainees, which considers the most important characteristics of the educational environment from the point of view of its impact on health on a concrete group of persons.

2.4. The courses «Pedagogical Health Saving Technologies», «Health and safety» for bachelors and «Health saving education», «Health saving technologies in educational process» for undergraduates are developed in Novosibirsk State Pedagogical University.

The course purpose - to assist in formation at students of common cultural and professional competences for design and application of health saving technologies in various social environments (it is carried out by formation of culture of health and HL, creation of optimum conditions of training, use of physical exercises, and also modern psychological influences on the personality).

The course is based on a method of projects. The method of projects is optimum for realization of innovative approaches in professional education. It is necessary to teach students to think, find and solve independently problems, to attract for this purpose the knowledge from different scientific areas, to form ability to predict results and possible consequences of different versions of the decision, abilities to establish relationships of cause and effect ties for realization of projects.

The program is developed on the basis of FSES, the Order of the Russian Federation «About education», article No. 51 and the priority national project «Education and Health», is focused on training of the highest qualification teacher, who:

1 ) is competent in the field of the organization of the health saving environment in EE, development of health's programs for educational institutions of different levels; is competent in design of individual educational trajectories for pupils with problems of health, and organisation a healthy lifestyle and safety; is competent in the 
organization of pedagogical researches for actual problems of education, health and HL; is competent in application of the health saving technologies, innovative pedagogical technologies and information and communication technologies in professional activity; is competent in management of educational institution from positions of health saving education;

2) is ready to work in establishments of primary, secondary, higher and additional education; is ready to work as the research associate in the scientific and educational centers, the health centers, recreation camps, institutes; head of methodical services and other structural divisions of educational institutions of different level.

2.5. We have formulated theoretical approaches to understanding of health and methods of its assessment which can be used for monitoring of health for all subjects of educational process.

The following principles were cornerstone of our methodological approach:

1. Health is a state of full physical, mental and social wellbeing, and not just absence of diseases and physical defects [4]. This definition is based on idea of organism's integrity and its components which characterize opportunities and ability of the personality to satisfy the biological, spiritual and social needs at perfect adaptation to external ecological and social conditions. We are based on medico-biological positions and give such definition: «Health - is ability of an organism to keep a homeostasis in the conditions of full adaptation to external factors and influences» $[1,3]$.

2. Level of health can be estimated quantitatively if to assume as a basis the size of reserve opportunities of the organism providing preservation of a homeostasis of his internal environment at adaptation to constantly changing conditions of the outside world (or to loadings) [4]. Thus, it is possible to use various load tests which allow to reveal the size of reserve opportunities of different systems and all organism as a whole.

3. The organism and the environment of its dwelling are a whole that causes mutual influences at each other. The model of such holistic approach is presented in Figure 1.

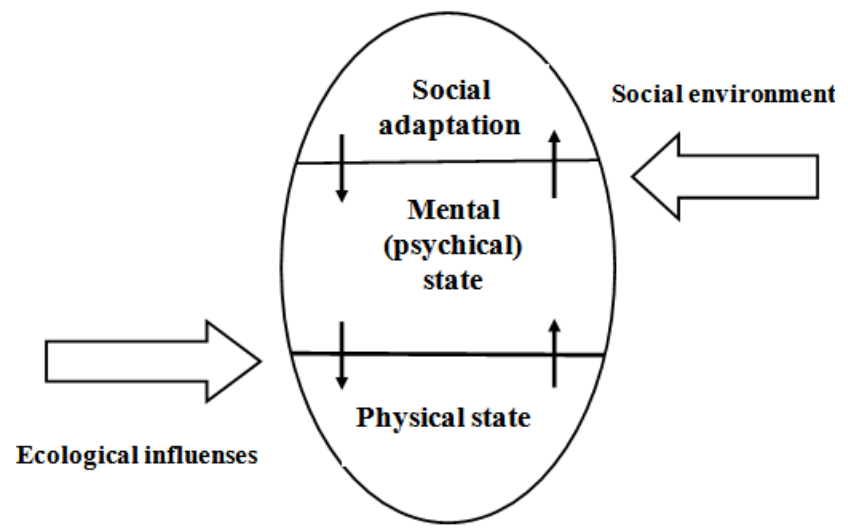

Figure 1. Model of complete approach to an assessment of personality's health

4. The children's organism is in continuous development therefore parameters which characterize its health, change in ontogenesis. Thus, it is important to consider not only existence or absence of available diseases, but control the dynamics of processes at an assessment of children's and teenagers's health.
5. Integrative approach is important for the health characteristic, it considers dynamics of physical development, a functional, psycho-emotional state of an organism and the individual and typological status of the person.

It was cornerstone of health monitoring system of the participants of educational process which was developed by us.

\section{Methods}

3.1. Monitoring of health is a dynamic screening diagnostics of physical development, functional reserves of an organism, neurodynamic indicators of nervous system, a mental state, specific constitutional features, adaptive (reserve) opportunities, a style of life and area in which happens educational and work of participants of educational process.

Monitoring of health means measurement and an assessment of various physical, psychophysiological and psychological parameters which can be quantitatively measured. They have high diagnostic efficiency as objectively reflect a state of health of the subject, allow to compare indicators in dynamics of ontogenesis and training, and also to predict its development on prospect.

3.2. Purpose of monitoring of pupils' health is on the basis of data on specific features and opportunities of an organism to provide the following:

- health preservation in the course of individual development and training;

- vocational guidance of pupils for an organism of profession's choice conscious and adequate to opportunities;

- assessment of health saving activity of educational institution;

- individual approach to the organization of teaching and educational process;

- correction of teaching and educational process for achievement of the greatest efficiency.

3.3. It is possible to solve such problems in the course of monitoring of students' and teachers' health:

- carrying out a self-assessment of physical, psychophysiological, personal, characterologic, professional and significant qualities, i.e. assessment of personal potential for self-correction and development;

- assessment of level of social and psychological adaptation and psychological climate in collective;

- forecast of risk of development of deviant forms of behavior, including dependences (narcotic, alcoholic, gambling);

- ensuring prevention of professional emotional burning out.

\section{Results}

4.1. We allocate the following levels when monitoring health:

- Physical (somatic) health which is estimated on a morphological and functional condition of all organs and systems, their interrelation that provides constancy of the internal environment of an organism (homeostasis) and its harmonious interaction with environment. 
- The psychical health includes:

- adequate self-assessment and sense of self-respect;

- ability to adapt for changing living conditions;

- ability effectively to satisfy the requirements and ability to compensate what can't be satisfied at present;

- confidence of the person that he operates the life;

- gender self-identification, socialization and selfrealization.

We developed electronic passports of health for monitoring of pupils', students' and teachers' health on the basis of the theoretical approaches given above $[3,4,5]$.

4.2. Advantages of electronic passports of health are:

- integrative approach to health as to the system state including indicators of physical, mental and social levels;

- computerization of all data that allows to create bank of health of various age, sexual and professional groups;

- quantitative expression of indicators which provides possibility of dynamic supervision and comparison of health's level of various groups, educational institutions, areas, etc.;

- comparative simplicity of diagnostics which doesn't demand the expensive equipment;

- possibility of transfer of results through the Internet;

- involvement of the subject in process of inspection that increases his personal interest in preservation and health development;

- opportunity to predict risk of development of deviant behavior, in due time to reveal psycho-somatic violations and to carry out their correction.

The developed computer options of techniques of a complex assessment of health have registration certificates which are granted by the Ministry of information technologies and communications of the Russian Federation and the certificate on the state registration of programs for computers. They are successfully introduced and are used in educational institutions in different regions of Russia and Kazakhstan.

4.3. Using these electronic passports we have evaluated the physical and mental health of about one thousand of 18-20-years-old - male and female students of different faculties were studied in process of their studing at Novosibirsk State Pedagogical University.

A survey showed that the level of social and psychological adaptation of students to the university was above average, and the main psycho-physiological characteristics were within the age-sex norms. The tendency to addictive behavior in the examined groups were not expressed. The personal potential of the majority surveyed students was characterized as below average. It was found sex differences of investigated parameters: the young men had higher motivation to success, good image memory, high speed of switching attention and viability compared with girls at the same age group. The girls had a high personal anxiety, hostility, and a high resistance to stress (Table 1, Table 2).

Table 1. Indicators of socially-psychological adaptation of students of 18-20 years $(M \pm m)$

\begin{tabular}{|c|c|c|c|}
\hline Indicators, point & females & males & $\begin{array}{c}\text { Significant } \\
\text { differences }\end{array}$ \\
\hline Adaptation & $65,5 \pm 0,4$ & $67,1 \pm 0,8$ & $\mathrm{~ns}$ \\
\hline Self-acceptance & $78,5 \pm 0,4$ & $78,7 \pm 0,8$ & $\mathrm{~ns}$ \\
\hline Acceptance of others & $67,8 \pm 0,5$ & $65,9 \pm 0,9$ & $\mathrm{~ns}$ \\
\hline Emotional comfort & $63,5 \pm 0,6$ & $66,4 \pm 1,2$ & $*$ \\
\hline Internal control & $67,5 \pm 0,5$ & $71,0 \pm 0,9$ & $* *$ \\
\hline Aspiration to domination & $61,1 \pm 0,6$ & $66,3 \pm 1$ & $* *$ \\
\hline
\end{tabular}

The note: in this and the subsequent tables asterisks note significant differences between females and males: $* \leq 0,05 ; * * \leq 0,01 ; * * * \leq 0,001$; ns-non significant.

Table 2. Average values of some psychological features of students of 18-20 years $(M \pm m)$

\begin{tabular}{|c|c|c|c|}
\hline Indicators, point & females & males & $\begin{array}{c}\text { Significant } \\
\text { differences }\end{array}$ \\
\hline Reactive uneasiness & $24,5 \pm 0,4$ & $23,4 \pm 0,7$ & $\mathrm{~ns}$ \\
\hline Personal uneasiness & $41,5 \pm 0,4$ & $37,4 \pm 0,6$ & $* * *$ \\
\hline Stress resistance & $40,1 \pm 0,3$ & $38,1 \pm 0,5$ & $* *$ \\
\hline Motivation to success & $18,3 \pm 0,2$ & $19,1 \pm 0,3$ & $*$ \\
\hline Volume of image memory & $8,3 \pm 0,1$ & $8,6 \pm 0,1$ & $*$ \\
\hline $\begin{array}{c}\text { Speed of attention switching, } \\
\text { seconds }\end{array}$ & $54,8 \pm 0,9$ & $50,5 \pm 0,9$ & $* *$ \\
\hline Viability & $113,02 \pm 1$ & $117,2 \pm 1,6$ & $*$ \\
\hline
\end{tabular}

Studing the morphological and functional state of the same students we have found that if the anthropometric parameters of the first-year students were in the normal range, differing between males and females (Table 3), about $50-60 \%$ of students by essencial functional indicators showing the physical working capacity and efficiency of blood circulation system were below average and low level (Table 4). On the basis of these findings we concluded the necessity of medical and teaching correction on physical education and sports lessons, as well as the participation of university dispensary to improving students physical state.

Table 3. Morphological indicators of surveyed students $(M \pm m)$

\begin{tabular}{|c|c|c|c|}
\hline Indicators & females & males & $\begin{array}{c}\text { Significant } \\
\text { differences }\end{array}$ \\
\hline Length of a body, sm & $164,1 \pm 0,2$ & $177,5 \pm 0,5$ & $* * *$ \\
\hline Body mass, $\mathrm{kg}$ & $59,5 \pm 0,4$ & $69,7 \pm 0,9$ & $* * *$ \\
\hline Ketle index, $\mathrm{kg} / \mathrm{m}^{2}$ & $22,0 \pm 0,1$ & $22,1 \pm 0,2$ & $\mathrm{~ns}$ \\
\hline
\end{tabular}

Table 4. Distribution of students on level of physical health (\%)

\begin{tabular}{|c|c|c|c|c|c|c|c|}
\hline \multirow{2}{*}{ Indicators } & \multicolumn{2}{|c|}{ Low and below an average levels } & \multicolumn{2}{c|}{ Average level } & \multicolumn{2}{c|}{ High and above an average levels } \\
\cline { 2 - 7 } & females & males & females & males & \multicolumn{2}{c|}{ females } & males \\
\hline Brush index & 81,3 & $65,8^{* *}$ & 11,4 & 15,8 & 7,3 & $18,4^{* *}$ \\
\hline Physical working capacity (PWC ${ }_{170}$ ) & 41,1 & $35,9^{*}$ & 41,4 & 37,7 & 17,5 & $26,4^{*}$ \\
\hline Efficiency of blood circulation system & 60,1 & 59,7 & 29,0 & 27,2 & 10,9 & 13,1 \\
\hline Level of physical health & 44,9 & 48,3 & 42,0 & 37,7 & 13,1 & 14,0 \\
\hline
\end{tabular}

possible due to realization of modular education: general

\section{Conclusions}

5.1. Formation in baccalaureates and masters of general cultural and professional scopes in field of health care is scientific module, professional module, scientific and methodical module, research and design module, organizational and administrative module. Thus, graduates of the master program have an opportunity of a choice of scientific, pedagogical and administrative career. 
5.2. Using in an educational process the program of monitoring of physical and mental health of students helps to form the professional scopes in field of health care, improves the skills of future teachers for practical healthcare, and gives information on their health necessary for further imrovement, stimulates their aspiration to get knowledge on health and its promotion.

\section{References}

[1] Abaskalova, N.P. Systemic approach to formation of a healthy way of life of subjects of educational process "school-high school": The monography. - Novosibirsk: NSPU, 2001. 325 p.

[2] Abaskalova, N.P. Problem of preservations and strengthenings of health of teachers. //Materials of. Republican with the international participation scientifically-practical conference «Monitoring of health and physical readiness of youth». Novosibirsk, 2009. P.6-9.

[3] Aizman, R. I. Valeology - synthesis of medicine and pedagogics //the Bulletin of Inter-regional Association «Public health services of Siberia». 2000. №1. P.45-56.
[4] Aizman, R. I. Medical and biologic and social aspects of health.//Physiological bases of health. / Under the editorship of Aizman R. I, Terner A.Ya.-Novosibirsk: Publishing house "Harmony". 2001. P. 19-35.

[5] Aizman, R. I. A technique of a complex estimation of health of pupils of general educational schools./ R.I.Aizman, N.I.Aizman, V. B. Rubanovich, A.V.Lebedev //The Registration certificate № 0320800711 from March, 27th, 2008 FSE scientific and technological centre "Information registry" № 12938.

[6] Kazin, E.M. Formation and health: medical and biologic and psihologo-pedagogical aspects: The monography. -- Kemerovo, 2010. 214 p.

[7] Melnikova, M.M. Sistem approach to the organisation health care formations in high school: The monography. - Novosibirsk: NSPU, 2004. 194 p.

[8] Novikov, A. Postindustrial society - a society of knowledge //Higher education in Russia. 2008. № 3. P. 109-117.

[9] The federal state educational standard of the basic general education - $<$ http://standart $>$. edu.ru//.

[10] Sal'nikov, N. Reformirovanie of the higher school: the concept of new educational model / N.Salnikov, S.Buruhin //Higher education in Russia. 2008. № 2. P. 3-11.

[11] Shishov, C.E School: monitoring of education quality / C.E.Shishov, V.A.Kal'ney - M, 2000. P.23-29. 